This article was downloaded by: [Kaiser Permanente], [Ms Kristin D. Neff]

On: 16 November 2014, At: 14:38

Publisher: Routledge

Informa Ltd Registered in England and Wales Registered Number: 1072954 Registered

office: Mortimer House, 37-41 Mortimer Street, London W1T 3J H, UK

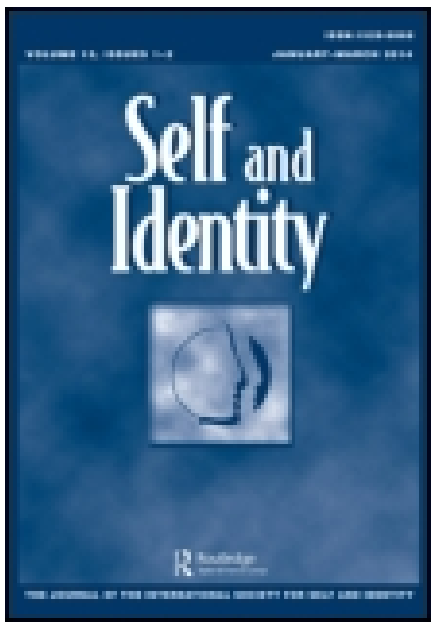

\title{
Self and Identity
}

Publication details, including instructions for authors and subscription information:

http:// www. tandfonline.com/loi/ psai20

\section{Presenting a Self-Compassionate Image After an Interpersonal Transgression}

Ashley Batts Allen ${ }^{a}$, J ennifer Barton ${ }^{b} \&$ Olivia Stevenson ${ }^{c}$

a Department of Psychology, University of North Carolina at Pembroke, Pembroke, NC 28372, USA

${ }^{b}$ Department of Psychology, University of North Florida, J acksonville, FL 32224, USA

' Department of Applied Statistics and Research Methods, University of Northern Colorado, Greeley, CO 80639, USA Published online: 21 Aug 2014.

To cite this article: Ashley Batts Allen, J ennifer Barton \& Olivia Stevenson (2015) Presenting a SelfCompassionate Image After an Interpersonal Transgression, Self and Identity, 14:1, 33-50, DOI: 10.1080/15298868. 2014.946958

To link to this article: http:// dx.doi.org/ 10.1080/ 15298868.2014.946958

\section{PLEASE SCROLL DOWN FOR ARTICLE}

Taylor \& Francis makes every effort to ensure the accuracy of all the information (the "Content") contained in the publications on our platform. However, Taylor \& Francis, our agents, and our licensors make no representations or warranties whatsoever as to the accuracy, completeness, or suitability for any purpose of the Content. Any opinions and views expressed in this publication are the opinions and views of the authors, and are not the views of or endorsed by Taylor \& Francis. The accuracy of the Content should not be relied upon and should be independently verified with primary sources of information. Taylor and Francis shall not be liable for any losses, actions, claims, proceedings, demands, costs, expenses, damages, and other liabilities whatsoever or howsoever caused arising directly or indirectly in connection with, in relation to or arising out of the use of the Content.

This article may be used for research, teaching, and private study purposes. Any substantial or systematic reproduction, redistribution, reselling, loan, sub-licensing, systematic supply, or distribution in any form to anyone is expressly forbidden. Terms \& 
Conditions of access and use can be found at http://www.tandfonline.com/page/termsand-conditions 


\title{
Presenting a Self-Compassionate Image After an Interpersonal Transgression
}

\author{
Ashley Batts Allen', Jennifer Barton ${ }^{2}$, and Olivia Stevenson ${ }^{3}$ \\ ${ }^{1}$ Department of Psychology, University of North Carolina at Pembroke, Pembroke, NC \\ 28372, USA \\ ${ }^{2}$ Department of Psychology, University of North Florida, Jacksonville, FL 32224, USA \\ ${ }^{3}$ Department of Applied Statistics and Research Methods, University of Northern \\ Colorado, Greeley, CO 80639, USA
}

Two studies investigate the presentation of self-compassion following an interpersonal transgression. In study $1(N=228)$, participants imagined letting someone down. Selfcompassionate participants were less likely to endorse self-critical statements and more likely to endorse self-compassionate statements. Study $2(N=208)$ investigated people's preference for selfcompassionate versus self-critical statements after someone let them down. Less self-compassionate participants preferred and were more likely to forgive someone who made self-critical statements. More self-compassionate participants preferred self-compassionate responses and were just as likely to forgive someone regardless of the type of response. These findings support the hypothesis that self-compassion leads to more self-compassionate presentations and presents a more nuanced understanding of responses to self-compassionate and self-critical presentations in an apology context.

Keywords: Self-compassion; Self-presentation; Apology; Transgression; Forgiveness.

In recent years, self-compassion has attracted the attention of researchers and laypersons as a mechanism through which people can pursue well-being. Proposed as a healthier selfattitude than self-esteem, self-compassion involves accepting one's flaws and inadequacies and responding to personal suffering with kindness and compassion (Neff, 2003; Neff \& Vonk, 2009). Research shows that self-compassion is an adaptive selfattitude and results in numerous benefits for the individual (Leary, Tate, Adams, Allen, \& Hancock, 2007; Neff, Rude, \& Kirkpatrick, 2007). In addition, some research suggests that this internal disposition produces desirable social effects by creating healthier and happier relationship partners (Yarnell \& Neff, 2012). Although some researchers have investigated the role of self-compassion in relationships, none have addressed the self-presentational component of self-compassion. Based on previous research, people who are selfcompassionate after committing an interpersonal transgression should experience internal benefits; however, self-presenting as self-compassionate may not be the best way to repair a relationship. This research will examine whether self-compassionate people who commit an interpersonal transgression are more likely to self-present as self-compassionate

Received 8 March 2014; accepted 16 July 2014; first published online 21 August 2014.

Correspondence should be addressed to: Ashley Batts Allen, Department of Psychology, University of North Carolina at Pembroke, 1 University Dr., Pembroke, NC 28372, USA. E-mail: ashley.allen@uncp.edu 
compared with people low in self-compassion. In addition, we will examine whether people prefer self-compassionate or self-critical self-presentations following an interpersonal transgression.

\section{Self-Compassion}

Self-compassion is the practice of being caring and understanding toward oneself in the midst of suffering. Neff (2003) suggests that self-compassion is composed of three parts: self-kindness, common humanity, and mindfulness. Being kind to oneself can involve positive and encouraging self-talk or engaging in behaviors meant to show kindness to the self. Common humanity entails a realization and understanding that personal suffering is part of the common human condition, and no one is alone in his or her pain. By drawing on this connection to others, self-compassionate people actually become less isolated and less self-focused. The final component, mindfulness, is the awareness and acknowledgment of one's suffering and the emotions that accompany suffering. However, mindfulness also implies equanimity as a mindful individual does not get carried away with these strong emotions or let those emotions control his or her behavior. Combined, these three components result in an individual who is attuned to personal suffering and responds to that suffering with kindness while acknowledging suffering as part of life.

\section{Self-Compassion and Intrapersonal Well-Being}

Results from numerous self-compassion studies support the hypothesis that selfcompassion is beneficial for one's personal well-being (Allen, Goldwasser, \& Leary, 2012; Allen \& Leary, 2014; Leary et al., 2007; Neff, Kirkpatrick, \& Rude, 2007; Neff, Rude, et al., 2007). Self-compassion is linked to a variety of positive traits such as optimism, positive affect, happiness, wisdom, and personal initiative (Neff, Rude, et al., 2007). In addition, self-compassion has a strong negative relationship with depression and anxiety-relationships that remain strong even after partialing out variance attributed to self-esteem (Neff, 2003). Correlational research also shows self-compassion is related to mastery goals, lower fear of failure, and more adaptive coping strategies such as positive cognitive restructuring when dealing with personal failures and setbacks (Allen \& Leary, 2010; Neff, Hsieh, \& Dejitterat, 2005). This research suggests that self-compassionate people may be more likely to pursue their goals and adapt to their situations.

These studies support that trait self-compassion positively relates to well-being. In addition, experimental studies find that self-compassion may cause increases in wellbeing. Self-compassion inductions result in less negative affect (Leary et al., 2007), higher self-improvement motivation (Breines \& Chen, 2012), higher rates of smoking cessation (Kelly, Zuroff, Foa, \& Gilbert, 2010), and more self-control among dieters (Adams \& Leary, 2007). Intervention research also demonstrates that teaching self-compassionate principles can have a lasting impact on one's well-being (Neff \& Germer, 2013). Results from the mindful self-compassion program show that participants who attended an 8-week training reported higher life satisfaction, more happiness, higher social connectedness, less depression, less anxiety, and less stress at a 6-month follow-up than wait list controls (Neff \& Germer, 2013).

Most of the research on self-compassion focuses on the benefits of self-compassion for the individual. However, if human beings are a social species who depend on the acceptance and esteem of other people, self-compassion should also be an adaptive trait that facilitates interpersonal relationships, in order to further contribute to well-being. 


\section{Self-Compassion and Interpersonal Well-Being}

Research is limited regarding the interpersonal effects of self-compassion. However, Neff and Beretvas (2012) found that self-compassionate individuals demonstrate more positive relationship behaviors as evaluated by their romantic partners. Furthermore, the romantic partners of self-compassionate people rated the quality of the relationship more positively. Specifically, self-compassionate partners were evaluated as being more emotionally connected, more autonomy seeking, and less aggressive in their relationships. Selfcompassionate individuals have more compassionate goals and fewer self-image goals in their relationships compared with people low in self-compassion (Crocker \& Canevello, 2008). Having more compassionate goals predicts trust and social support leading to healthier relationships for the people involved. Moreover, Yarnell and Neff (2012) found that self-compassionate participants were more likely to use compromising strategies instead of subordinating strategies when resolving conflict. These self-compassionate participants also felt more authentic, experienced less emotional turmoil, and higher relational well-being than their peers low in self-compassion.

Other research findings present a more nuanced picture of self-compassion in relationships, suggesting that the impact of self-compassion on relational well-being may depend on dispositional characteristics (Baker \& McNulty, 2011). In particular, Baker and McNulty (2011) found that while self-compassion in women led to relational well-being, the relationship between self-compassion and relational well-being for men was dependent on conscientiousness. More conscientious men who were also self-compassionate demonstrated higher relational well-being, whereas less conscientious men who were selfcompassionate showed poorer relational well-being than less self-compassionate men. This research study is the first to present a potential downside of self-compassion showing that high self-compassion might not always be beneficial. Further, Neff and Pommier (2013) found self-compassion is linked to empathic concern and compassion toward humanity for a community adult sample. Yet, they found no relationship between selfcompassion, altruism, and empathy in college students. Although mixed, the findings suggest that self-compassionate people may handle relationship conflict better. Therefore, one would expect self-compassion to play a role in repairing relationships following transgressions.

\section{Self-Compassion and Interpersonal Transgressions}

Although some research suggests that self-compassion can be beneficial to relationships, no research has focused on perceptions of self-compassion following an interpersonal transgression. People are motivated to be accepted and valued by other people (Baumeister \& Leary, 1995); therefore, people take great care in managing their impressions to facilitate social acceptance (Leary \& Allen, 2011a). Following an interpersonal transgression, the individual may find him or herself out of favor and must work to repair the relationship. Leary and Allen (2011b) found many personality variables impact how people construct and evaluate their self-presentations. Thus, selfcompassion may impact people's self-presentations as they strive to repair and restore relational ties. For example, self-compassionate individuals are more likely to accept responsibility for their mistakes (Leary et al., 2007). Therefore, self-compassionate people may be more likely to show remorse for their actions and offer to compensate for the mistake. Both remorse and compensation often lead to favorability and forgiveness from others (Bottom, Gibson, Daniels, \& Murnighan, 2002; Darby \& Schlenker, 1982; Schlenker, 1980). 
In addition, self-compassionate people may be less likely to engage in self-degradation and self-criticism when seeking forgiveness. Yarnell and Neff (2012) found selfcompassionate people were less subordinate and more authentic in their conflict resolution strategies. So, personal self-compassion should dissuade the individual from making selfstatements contradicting this internal self-attitude. On the contrary, feelings of selfcompassion following an interpersonal transgression may lead to outward expressions of compassion in hopes of receiving forgiveness and restoring relational value. These selfpresentations should be more authentic when interacting with close others as opposed to strangers with the exception of romantic partners where the motivation to manage one's impression is particularly high (Leary et al., 1994). In addition, verbalizing selfcompassion may not always be seen as socially acceptable, especially in a transgression situation. Therefore, people should feel more allowance to express self-compassion with a close friend than an acquaintance.

The purpose of study 1 is to assess how self-compassionate people present themselves following a transgression-both to the person they transgressed against and a neutral third party member. Because self-compassionate responses may seem excusatory, we anticipate that people may present themselves more self-compassionately with a third-party member than the person they hurt. We hypothesize that self-compassionate individuals will be more likely to say self-compassionate statements (and less likely to say self-critical statements) following a transgression than participants low in self-compassion. We anticipate that these effects may be moderated by the closeness of the relationship. We expect trait self-compassion to result in more self-compassionate responses for close friends than strangers and romantic partners. People should feel more comfortable expressing their self-compassion when apologizing to a friend because they should feel free to show a more authentic self (Leary et al., 1994). In addition, supporting previous research showing men are more self-compassionate than women (Neff, 2003; Neff et al., 2005), we expect men to endorse self-compassionate statements more than women.

\section{Study 1 Method}

\section{Participants}

Participants were 228 workers (134 women and 94 men) recruited from Mechanical Turk, an online crowdsourcing system powered by Amazon.com. Only workers accessing the survey from within the USA were able to participate in the study. Participants' ages ranged from 18 to 73 years $(M=37.02, \mathrm{SD}=13.24)$. Varying ethnicities were reported with $78.5 \%(n=179)$ Caucasian/White, $11 \%(n=25)$ African-American (Black), $8.3 \%$ $(n=19)$ Asian-American, $4.8 \% \quad(n=11)$ Hispanic/Mexican-American/Latino, $2.2 \%$ $(n=5)$ Asian (including Indian subcontinent), $1.8 \%(n=4)$ Native American/Alaska Native, and $0.4 \%(n=1)$ other (the total exceeds $100 \%$ as people were allowed to select multiple ethnicities). Participants were compensated $\$ 0.40$ for their participation. Six participants were removed from the final analyses because their written responses indicated that they did not read the study. The final analyses include 222 participants.

\section{Procedure}

Participants were recruited through Mechanical Turk, an online recruitment tool operated by Amazon.com. Mechanical Turk users were able to self-select to participate in the study. After reading the informed consent information, participants selected "next" to proceed to the study. Participants were asked to imagine a scenario in which they made a mistake that 
negatively impacted someone else. The prompts differed by conditions of closeness: acquaintance, close friend, and romantic partner. Participants were randomly assigned to one of the three conditions. Participants were told to imagine an acquaintance/close friend/romantic partner had asked them to pick up their niece from school because they were detained by a work emergency. Participants were also asked to imagine that they were 45 minutes late picking up the child from school. As a result, the acquaintance/close friend/romantic partner must pay a late fee and the child is very upset. On reading the scenario, participants were asked to spend 3 minutes writing what they would say to the person in the scenario the next time they spoke to them. Following the experimental manipulation, participants indicated how likely they would be to say a variety of selfcompassionate statements, self-critical statements, and apology statements to the person in the scenario. Participants then indicated how likely they would be to say these statements to another person when discussing the event. Participants finished by completing several individual difference measures (the self-compassion scale was the last measure) and some demographic information. Lastly, participants were debriefed.

\section{Measures}

Self-compassion statements. Participants indicated how likely they would be to say six self-compassionate statements on a scale from 1 (not at all) to 5 (extremely). The selfcompassion statements were adapted from the Self-compassion Scale (Neff, 2003), and two items were chosen to represent each of the three positive subscales: self-kindness ( $I$ am not perfect and I make mistakes sometimes), common humanity (Everyone makes mistakes from time to time), and mindfulness (I am upset with myself, but I'm not going to get carried away with my emotions). In addition, a scale measuring how likely participants reported they were to say these self-compassionate statements to another person was created with the same six items mentioned earlier.

In addition, two coders independently assessed whether participants' free responses showed positive elements of self-compassion including self-kindness, common humanity, and mindfulness $(\kappa=.75)$. Any disagreement was resolved by the principal investigator. An example of a self-compassionate response was

I would tell my friend that I was sorry for being late. I did not intend to be late. It just so happened that I ran into some circumstances that prevented me from arriving on time. I hope you can understand that I did not intentionally try to come late. I had full intention of keeping my word, but sometimes situations come up that prevent you from doing what you wanted to do.

Only $8.6 \%$ of participants expressed self-compassion in their free response.

Self-critical statements. Participants indicated how likely they would be to say six self-critical statements on a scale from 1 (not at all) to 5 (extremely). The self-critical statements were adapted from the Self-compassion Scale (Neff, 2003), and two items were chosen to represent each of the three negative subscales: self-judgment (I am so irresponsible), isolation (Anyone else would have planned better and been on time), and over-identification (I should never be trusted again). Additionally, a scale measuring how likely participants reported they were to say these self-compassionate statements to another person was created with the same six items mentioned earlier.

Two independent coders assessed whether participants' free responses showed negative elements of self-compassion: self-judgment, isolation, and overidentification $(\kappa=.59)$. An example of a self-critical response was 
I am so sorry. I feel awful. I let you and your kid down. I will pay the extra fee. I feel like a horrible human being, letting you down when you trusted me with the most precious person in your life. I hope you can forgive me.

Out of all the responses, $21.2 \%$ provided a self-critical response.

Remorsefulness. Participants indicated how likely they would be to say three remorseful statements on a scale from 1 (not at all) to 5 (extremely). The remorsefulness items included the statements "I am sorry," "I promise to never let you down again," and "I'll pay the late fee." These items were assessed separately, as they did not have a high Cronbach's $\alpha$.

Two independent coders assessed whether participants apologized in their free response $(\kappa=.91)$, offered to pay the late fee $(\kappa=.96)$, and offered to make it up in some other way $(\kappa=.88)$. Out of all participant responses, $93.7 \%$ of participants apologized, $64.4 \%$ of participants offered to pay the late fee, and $42.3 \%$ of participants offered to make it up in some other way. Because offers to pay the late fee and offers to make it up in some other way are both efforts to repair the relationship, these variables were combined such that participants received a score of 1 if they offered to either pay the late fee and/or make it up in some other way and a score of 0 if they did not make an offer to repair the relationship. In total, $76.6 \%$ of participants offered to repair the relationship.

Trait self-compassion. Participants completed the Self-compassion Scale (Neff, 2003) to assess trait self-compassion. The scale includes 26 self-report statements using a 1 (almost never) to 5 (almost always) rating scale and measures six subscales: selfkindness (I try to be loving towards myself when I'm feeling emotional pain), selfjudgment (When times are really difficult, I tend to be tough on myself), common humanity (I try to see my failings as part of the human condition), isolation (When I'm feeling down, I tend to feel like most people are probably happier than I am), mindfulness (When I fail at something important to me I try to keep things in perspective), and over-identification (When something painful happens I tend to blow the incident out of proportion). Negatively worded items were reverse scored; therefore, higher numbers indicate high trait self-compassion.

\section{Study 1 Results}

\section{Verbalizing Self-Compassion and Self-Criticism}

Table 1 provides descriptive information for continuous variables used in study 1 . Repeated Measures Analysis of Variance was used to investigate participants' endorsement of self-compassionate versus self-critical responses. Participants' endorsement of self-compassionate versus self-critical statements was the repeated variable. Closeness, gender, and mean-centered trait self-compassion were also entered as predictors in the model along with their respective two and three -way interactions. Aiken and West's (1991) simple slopes strategy was used to disentangle significant two-way interactions involving self-compassion.

Statements to the target. A main effect of response type, $F(1,198)=13.40, p<.001$, $\eta_{p}^{2}=.063$, revealed that participants were more likely to endorse saying selfcompassionate statements $(M=2.09, \mathrm{SD}=.95)$ than self-critical statements $(M=1.91$, $\mathrm{SD}=.82)$. A main effect of gender, $F(1,198)=13.19, p<.001, \eta_{p}^{2}=.062$, showed that men $(M=2.10, \mathrm{SD}=.87)$ were significantly more likely to endorse saying the statements 
TABLE 1 Descriptives for Continuous Variables in Study 1

\begin{tabular}{lcccccc}
\hline & $M$ & SD & $A$ & Skewness & Kurtosis & $N$ \\
\hline Trait SC & 3.05 & .77 & .95 & .01 & -.09 & 210 \\
SelfComp Target & 2.11 & .96 & .86 & .54 & -.76 & 222 \\
SelfCrit Target & 1.92 & .81 & .79 & .95 & .43 & 222 \\
SelfComp Other & 2.34 & .96 & .85 & .25 & -.87 & 222 \\
SelfCrit Other & 1.96 & .84 & .85 & .89 & .56 & 222 \\
Apology & 4.74 & .63 & - & -2.89 & 9.47 & 222 \\
Late fee & 4.57 & .87 & - & -2.41 & 5.85 & 222 \\
Let down & 3.52 & 1.41 & - & -.59 & -.96 & 222 \\
\hline
\end{tabular}

Note: Trait SC, trait self-compassion; SelfComp Target, self-compassionate statements to the target; SelfCrit Target, self-critical statements to the target; SelfComp Other, self-compassionate statements to another person; SelfCrit Other, self-critical statements to another person.

to the target than women $(M=1.79, \mathrm{SD}=.76)$. These main effects were qualified by a significant three-way interaction between gender, response type, and trait self-compassion, $F(1,198)=6.81, p=.010, \eta_{p}^{2}=.033$. Simple effects tests with a Bonferroni adjustment at three levels of self-compassion ( $-1 \mathrm{SD}, M, 1 \mathrm{SD}$ ) were used to interpret the three-way interaction. Men endorsed the self-compassionate and self-critical statements more than women. Men and women low in self-compassion did not differ in their likelihood of saying self-compassionate or self-critical statements; however, men and women high in selfcompassion were more likely to say self-compassionate statements than self-critical statements. Trait self-compassion increased the likelihood of men to say self-compassionate statements and decreased their likelihood of endorsing self-critical statements. For women, self-compassion did not significantly predict their likelihood of saying self-compassionate statements, but it did decrease their likelihood of saying self-critical statements.

Given the small number of participants who spontaneously provided a selfcompassionate or self-critical response, relationship closeness and gender were not investigated as predictors. Instead, two-tailed point biserial correlations were used to determine the relationship between trait self-compassion and self-compassionate and selfcritical free responses. Trait self-compassion was marginally positively correlated with self-compassionate free responses $\left(r_{\mathrm{pb}}=.13, p=.066\right)$ and was not correlated with selfcritical free responses $\left(r_{\mathrm{pb}}=-.10, p=.141\right)$.

Statements to another person. Similar to the previous findings, a main effect of response type, $F(1,198)=42.65, p<.001, \eta_{p}^{2}=.177$, showed that participants were significantly more likely to endorse saying self-compassionate statements $(M=2.31$, $\mathrm{SD}=.94)$ to another person than self-critical statements $(M=1.93, \mathrm{SD}=.83)$. A main effect of gender, $F(1,198)=9.05, p=.003, \eta_{p}^{2}=.044$, showed that men $(M=2.07$, $\mathrm{SD}=.90)$ were more likely to endorse saying the statements to another person than women $(M=1.84, \mathrm{SD}=.76)$. These main effects were qualified by a significant response type by gender interaction, $F(1,198)=3.79, p=.053, \eta_{p}^{2}=.019$. Simple main effect tests using a Bonferroni adjustment (shown in Figure 1) revealed both men and women were more likely to endorse saying self-compassionate statements $(M=2.57, \mathrm{SD}=.97 ; M=2.13$, $\mathrm{SD}=.94$, respectively) to another person than self-critical statements $(M=2.07$, $\mathrm{SD}=.90 ; M=1.84, \mathrm{SD}=.76$, respectively). However, men were significantly more likely to endorse self-compassionate statements compared to women. Men and women did not significantly differ in their likelihood of endorsing self-critical statements to another person. A significant response type by trait self-compassion interaction, $F(1,198)=46.50$, 


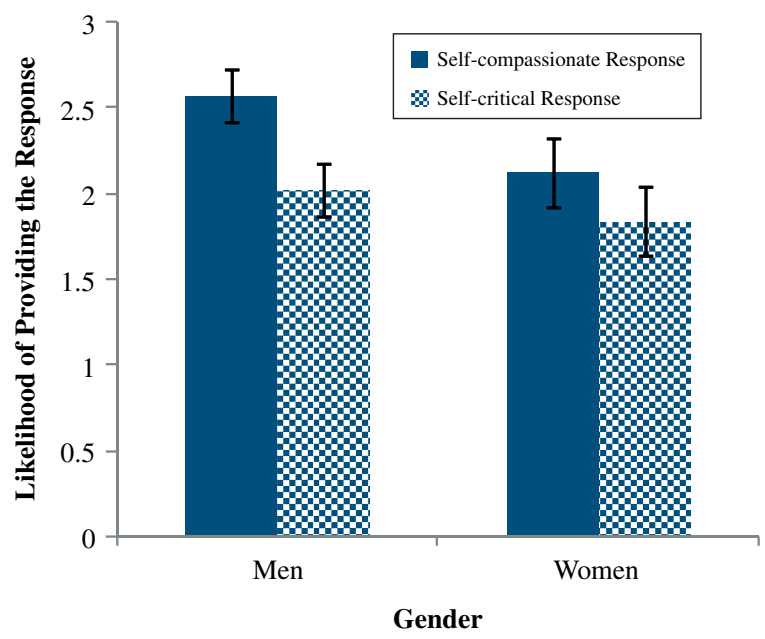

FIGURE 1 Significant response type by gender interaction for the likelihood of saying self-compassionate versus self-critical statements to another person in study 1 . Each mean includes a $95 \%$ confidence interval.

$p<.001, \eta_{p}^{2}=.190$, found that participants low in self-compassion did not differ in their likelihood of saying a self-compassionate versus self-critical statement to another person. However, self-compassionate participants were significantly more likely to endorse saying a self-compassionate statement over a self-critical statement.

\section{Relationship Repair Strategies}

Participants' endorsement of saying "I'm sorry" following the personal transgression was heavily skewed revealing $82 \%$ of the sample reported being extremely likely to say they were sorry. Similarly, $74 \%$ of the sample reported being extremely likely to say they would pay the late fee. Hierarchical regression analyses were used to investigate whether mean-centered trait self-compassion, closeness, and gender predicted the likelihood that participants would endorse saying "I will never let you down again." Trait selfcompassion was entered in step 1, dummy-coded closeness was entered in step 2, gender was entered in step 3, self-compassion by condition interaction was entered in step 4, selfcompassion by gender interaction was entered in step 5 , gender by condition interaction was entered in step 6, and the three-way interaction was entered in step 7. The only significant effect was a main effect of gender showing women $(M=3.74, \mathrm{SD}=1.36)$ were more likely to endorse saying they would never let the person down again than men $(M=3.20, \mathrm{SD}=1.43), \beta=.16, t=2.35, p=.004$.

As before, two-tailed point biserial correlations were used to assess the relationship between trait self-compassion and the participants' apology and repair free responses. Trait self-compassion was not related to whether the participant apologized $\left(r_{\mathrm{pb}}=.001\right.$, $p=.989)$ or whether they offered to repair the relationship $\left(r_{\mathrm{pb}}=.04, p=.583\right)$.

\section{Study 1 Discussion}

Study 1 shows that trait self-compassion predicts what people say following an interpersonal transgression. Self-compassionate participants were less likely to endorse 
saying self-critical statements to the target than participants low in self-compassion. Selfcompassionate men were more likely to endorse saying self-compassionate statements as compared to men low in self-compassion, but this effect was not found for women. Similar findings were found for the likelihood of making self-compassionate versus self-critical statements to another person although these effects were not moderated by gender. The coded free responses generally supported the finding that self-compassionate participants were more likely to provide positive self-compassionate responses and less likely to provide self-critical responses when compared to less self-compassionate participants. Previous research found that self-compassionate individuals are more likely to have selfcompassionate thoughts and less likely to have self-critical thoughts (Allen \& Leary, 2014), whereas this study is the first to examine expression of those thoughts following an interpersonal transgression. These findings support the hypothesis that self-compassionate individuals present themselves differently by expressing more self-compassion and less self-criticism than participants low in self-compassion.

Our hypothesis regarding gender was partially supported. Not only were men more likely than women to endorse self-compassionate statements, but they were also more likely to endorse self-critical statements. Further, while self-compassionate men were more likely to endorse self-compassionate statements, this relationship did not occur for women. Due to ceiling effects, we did not find support for the hypothesis that selfcompassionate participants would be more likely to apologize and offer compensation. In addition, we did not find any moderating effects of closeness, leading to the conclusion that one's presentation of self-compassionate versus self-critical responses does not depend on the closeness of one's relationship to the target.

Given self-compassionate individuals are more likely to express self-compassion following an interpersonal transgression, we were interested in how these responses would be received by an injured party. In study 1, 82\% of the participants reported being extremely likely to apologize and $93.7 \%$ of participants apologized in their free response. Previous research shows that using self-criticism in an apology elicits support from the injured party and reassures the transgressor of his or her social acceptance (Goffman, 1971; Jones \& Pittman, 1982). We predicted that people would prefer to hear self-critical statements during an apology as opposed to self-compassionate statements. Therefore, study 2 uses the same interpersonal transgression scenario, but investigates the extent to which participants would want a transgressor to say self-compassionate versus self-critical statements following the transgression.

Although relationship closeness did not moderate the relationship between trait selfcompassion and endorsing self-compassionate responses in study 1 , we anticipated that people would be more willing to accept self-compassionate responses from close friends and romantic partners as opposed to acquaintances. Research on forgiveness shows people are more likely to forgive others with whom they have close relationships (McCullough et al., 1998); therefore, we anticipate that participants will be more likely to forgive close friend and romantic partners than acquaintances. In line with findings from study 1 , we expected men to respond more favorably to the self-critical and self-compassionate statements than women.

\section{Study 2 Method}

\section{Participants}

Participants were 208 workers (109 women, 97 men, 2 unidentified) recruited from Mechanical Turk. Once again, only workers accessing the survey from within the USA 
were able to participate in the study. Participants' ages ranged from 18 to 71 years $(M=33.55, \mathrm{SD}=12.19)$. Varying ethnicities were reported with $72.1 \% \quad(n=150)$ Caucasian/White, 12\% $(n=25)$ African-American (Black), 9.1\% $(n=19)$ AsianAmerican, 3.8\% $(n=8)$ Hispanic/Mexican-American/Latino, 1.9\% $(n=4)$ Asian (including Indian subcontinent), $1.9 \%(n=4)$ Native American/Alaska Native, and $1.4 \%$ $(n=3)$ other (the total exceeds $100 \%$ as people were allowed to select multiple ethnicities). Participants were compensated $\$ 0.40$ for their participation. Four participants were removed from the final analyses because they indicated participating in study 1 . The final analyses included 204 participants.

\section{Procedure}

As in study 1, participants were recruited through Mechanical Turk, an online recruitment tool operated by Amazon.com. Mechanical Turk users were able to self-select to participate in the study. After reading informed consent information, participants selected "next" to proceed to the study. Participants were asked to imagine a scenario in which someone made a mistake that impacted the participant. The prompts differed by conditions of closeness: acquaintance, close friend, and romantic partner. Participants were randomly assigned to one of the three conditions. Participants were told to imagine that an acquaintance/close friend/romantic partner was supposed to pick up their niece from school because they were detained by a work emergency. Participants were also asked to imagine their acquaintance/close friend/romantic partner was 45 minutes late picking the child up from school. As a result, the participant must pay a late fee and the child is very upset. Upon reading the scenario, participants were asked to spend 3 minutes writing what they would want the transgressor to say to them the next time they spoke to each other. Following the experimental manipulation, participants indicated to what extent they would want the transgressor to say a variety of self-compassionate statements, self-critical statements, and apology statements to them. Participants also indicated how likely they would be to forgive the transgressor for the transgression if they said that statement. Participants finished by completing the self-compassion scale (Neff, 2003) and some demographic information. Lastly, participants were debriefed.

\section{Measures}

Self-compassion statements. Participants indicated to what extent they wanted the transgressor to say six self-compassionate statements on a scale from 1 (not at all) to 5 (extremely). The self-compassion statements were identical to the ones used in study 1. Participants also indicated to what extent they would forgive the transgressor if they said the self-compassionate phrases.

As in study 1, two coders independently assessed whether participants' free responses showed positive elements of self-compassion $(\kappa=.57)$ with the principal investigator resolving disagreements. Although participants were instructed to write what they would want their acquaintance/friend/romantic partner to say, many participants responded to the prompt in the third person. Therefore, most of the self-compassionate responses showed evidence of the participants' compassion rather than the participant wanting a verbal selfcompassionate response from the transgressor. An example of a self-compassionate response was "I would simply like an apology. Everyone makes mistakes, the apology is the important part." Only $7.8 \%$ of participants expressed wanting a self-compassionate response from the transgressor. 
Self-critical statements. Participants indicated to what extent they wanted the transgressor to say six self-critical statements on a scale from 1 (not at all) to 5 (extremely). The self-critical statements were identical to the ones used in study 1 . Participants also indicated to what extent they would forgive the transgressor if they said the self-critical phrases.

Two independent coders also assessed whether participants' free responses showed negative elements of self-compassion $(\kappa=.71)$ with the principal investigator resolving any disagreements. An example of a self-critical response was "I would want them to tell me they are extremely sorry for being late to pick her up. That they were irresponsible and selfish and that they know what they did was wrong and inexcusable." Out of all the responses, $16.7 \%$ provided a self-critical response.

Remorsefulness. Two independent coders assessed whether participants wanted the transgressor to apologize $(\kappa=.75)$, offer to pay the late fee $(\kappa=.89)$, and offer to make it up in some other way $(\kappa=.77)$. Out of all participant responses, $85.3 \%$ of participants wanted an apology, $52.9 \%$ of participants wanted an offer to pay the late fee, and $28.4 \%$ of participants wanted the transgressor to make it up in some other way. Because offers to pay the late fee and offers to make it up in some other way are both efforts to repair the relationship, these variables were combined such that participants received a score of 1 if they wanted an offer to either pay the late fee and/or make it up in some other way and a score of 0 if they did not specify an offer to repair the relationship. In total, $64.2 \%$ of participants wanted an offer to repair the relationship.

Trait self-compassion. As in study 1, participants completed the Self-Compassion Scale (Neff, 2003) to assess trait self-compassion.

\section{Study 2 Results}

Table 2 provides descriptive information for all continuous variables in study 2 . Repeated Measures Analysis of Variance was used to determine whether participants desired selfcritical responses from others over self-compassionate responses. The extent to which participants wanted the transgressor to make self-compassionate statements versus selfcritical statements was the repeated variable. Gender, mean-centered trait selfcompassion, and closeness condition were also entered as predictors along with their respective two-way and three-way interactions. No three-way interactions were significant and were subsequently removed from the analyses. Aiken and West's (1991) simple slopes strategy was used to disentangle significant two-way interactions involving selfcompassion.

TABLE 2 Descriptives for Continuous Variables in Study 2

\begin{tabular}{lcccccc}
\hline & $M$ & SD & $A$ & Skewness & Kurtosis & $N$ \\
\hline Trait SC & 3.04 & .59 & .95 & -.25 & .23 & 204 \\
SelfComp & 2.09 & .95 & .87 & .76 & -.38 & 204 \\
SelfCrit & 2.07 & .90 & .87 & .71 & -.33 & 204 \\
SelfComp Forgive & 2.33 & .95 & .85 & .59 & -.15 & 204 \\
SelfCrit Forgive & 2.52 & .95 & .81 & .49 & -.07 & 204 \\
\hline
\end{tabular}

Note: Trait SC, trait self-compassion; SelfComp, self-compassionate statements; SelfCrit, selfcritical statements; SelfComp Forgive, forgiveness if transgressor gives self-compassionate statements; SelfCrit Forgive, forgiveness if transgressor gives self-critical statements. 


\section{Verbalizing Self-Compassion and Self-Criticism}

A Repeated Measures ANOVA revealed a main effect of gender showing that men $(M=2.20, \mathrm{SD}=.93)$ were more likely than women $(M=1.95, \mathrm{SD}=.90)$ to endorse any of the responses regardless of the type of response, $F(1,192)=6.71, p=.010, \eta_{p}^{2}=.034$. More interestingly, a trait self-compassion by response type interaction revealed that participants who were low in self-compassion wanted the transgressor to respond with more self-critical than self-compassionate statements, whereas participants high in selfcompassion desired more self-compassionate responses than self-critical responses from the transgressor, $F(1,192)=7.51, p=.007, \eta_{p}^{2}=.038$ (see Figure 2). No other effects were found to be significant.

Participants were also asked the extent to which they would be likely to forgive the transgressor if they provided certain responses. A Repeated Measures ANOVA revealed a significant main effect of response type showing participants were more likely to forgive the transgressor when they made self-critical $(M=2.52, \mathrm{SD}=.95)$ as opposed to selfcompassionate statements $(M=2.32, \mathrm{SD}=.95), F(1,190)=8.24, p=.005, \eta_{p}^{2}=.041$. This main effect was qualified by a significant trait self-compassion by response type interaction showing that less self-compassionate participants were more likely to forgive the transgressor when he or she made self-critical versus self-compassionate statements. On the contrary, more self-compassionate participants were equally likely to forgive a transgressor if he or she made self-compassionate or self-critical statements, $F(1$, $190)=8.78, p=.004, \eta_{p}^{2}=.044$ (see Figure 3). A significant response type by closeness interaction suggested that participants were more likely to forgive acquaintances and close friends when they provided self-critical statements $(M=2.51, \mathrm{SD}=.93 ; M=2.69$, $\mathrm{SD}=.95$, respectively) as opposed to self-compassionate statements $(M=2.30$, $\mathrm{SD}=.93 ; M=2.21, \mathrm{SD}=.89$, respectively). Participants were not more likely to forgive romantic partners for self-critical statements $(M=2.37, \mathrm{SD}=.95)$ over selfcompassionate statements $(M=2.43, \mathrm{SD}=1.01), \quad F(1,190)=4.14, p=.017$, $\eta_{p}^{2}=.041$. No other pairwise comparisons were significant.

Participants' coded responses were analyzed by investigating the relationship between trait self-compassion and the participants' likelihood of wanting a self-compassionate

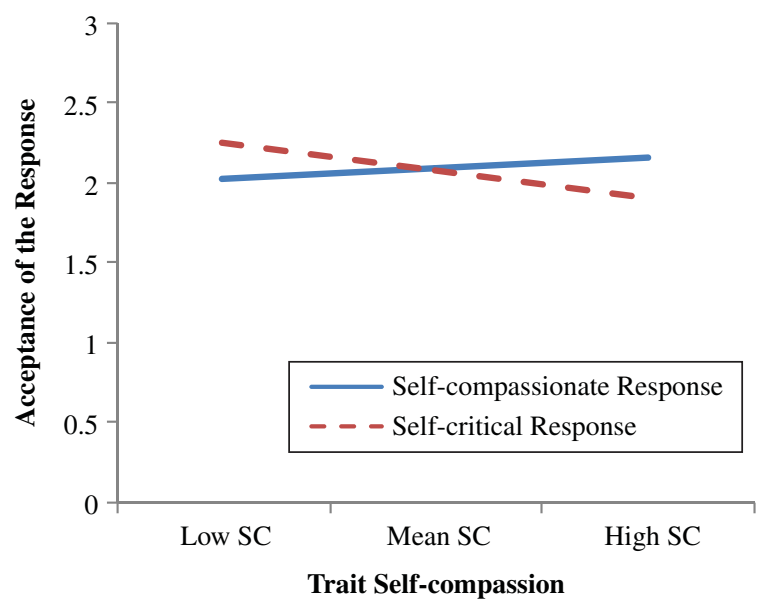

FIGURE 2 Significant self-compassion by response type interaction on the extent to which people would prefer to hear self-compassionate versus self-critical statements in study 2 . 


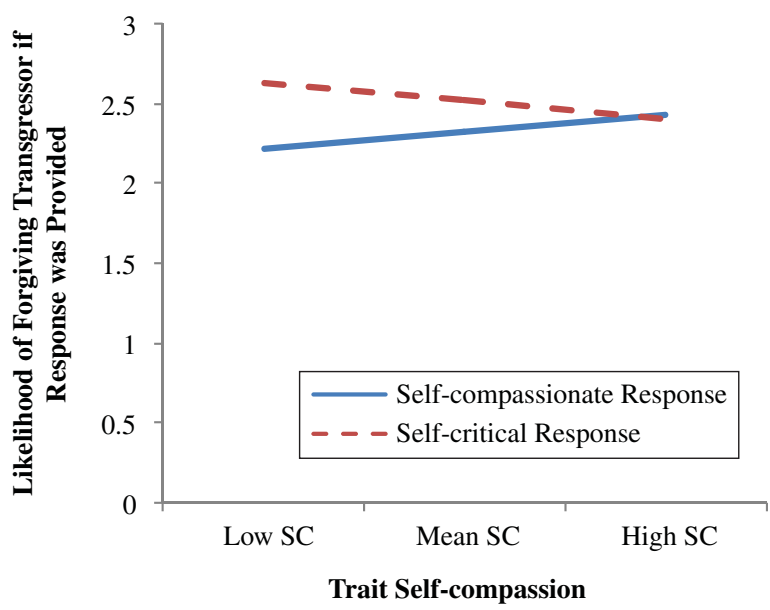

FIGURE 3 Significant self-compassion by response type interaction on the extent to which people would forgive someone for a transgression if he/she provided a selfcompassionate versus self-critical statement in study 2 .

response, a self-critical response, an apology, and/or an offer to repair the relationship from the transgressor. Two-tailed point biserial correlations showed that trait selfcompassion negatively correlated with self-critical free responses $\left(r_{\mathrm{pb}}=-.14, p=.053\right)$. Trait self-compassion did not correlate with participants' desire for the transgressor to provide a self-compassionate response $\left(r_{\mathrm{pb}}=.06, p=.381\right)$, expectation of an apology $\left(r_{\mathrm{pb}}=-.10, p=.161\right)$, or offer to repair the relationship $\left(r_{\mathrm{pb}}=-.01, p=.918\right)$.

\section{Study 2 Discussion}

The purpose of study 2 was to determine how people respond to a self-compassionate or self-critical presentation from someone who let them down. Overall, participants preferred presentations reflecting their own self-attitudes. Self-critical participants preferred and were more likely to forgive transgressors who presented themselves self-critically as opposed to self-compassionately. Self-compassionate participants preferred selfcompassionate statements and were just as likely to forgive transgressors who presented themselves self-critically as those who presented self-compassionately. Coded responses showed that self-compassionate participants were less likely to expect the transgressor to be self-critical and were also less likely to expect an apology; however, self-compassion did not predict expectations of a self-compassionate response as hypothesized.

These findings partially support previous research showing people are more likely to offer forgiveness and support to someone who harmed them when their apology is accompanied by self-degradation (Goffman, 1971; Jones \& Pittman, 1982). However, our findings present a more nuanced effect in that this relationship is only true for people who are more self-critical. Yarnell and Neff (2012) found that trait self-compassion scores were positively correlated for relationship partners supporting the notion that people are attracted to others who share a similar self-attitude. Perhaps this attraction partially explains why people prefer presentations of self-attitudes reflecting their own.

As predicted, men endorsed self-compassionate and self-critical statements more than women. Closeness played a small role in whether participants would be more likely to forgive a transgressor who provided self-critical versus self-compassionate responses. 
Participants preferred self-critical presentations to self-compassionate presentations for acquaintances and close friends, but indicated no preference for relationship partners. Based on forgiveness research, we anticipated that the type of response would be less important to forgiveness when the relationship was close as participants should be motivated to maintain a positive view of their relationship (McCullough et al., 1998). The finding partially supported our hypothesis in that participants' preference for self-critical over self-compassionate statements diminished for romantic partners. Previous research shows victims of transgressions respond differently depending on whether the transgression is committed by a romantic or non-romantic partner (Kearns \& Fincham, 2005). People in romantic relationships are more motivated to maintain a positive perspective of the relationship, thus they are less likely to catastrophize negative outcomes. Within this study, participants may not have preferred self-critical presentations from their romantic partners out of a desire to view the relationship in the most positive light possible.

\section{General Discussion and Conclusion}

These studies investigated how trait self-compassion impacts people's self-presentations following an interpersonal transgression as well as how others responded to these selfpresentations. In addition, we were interested in whether these effects would be moderated by gender and relationship closeness. The findings supported our hypothesis that selfcompassionate participants would be more likely to say self-compassionate statements and less likely to say self-critical statements than participants low in self-compassion. We found this effect consistently for men, but self-compassion did not relate to the likelihood that women would say self-compassionate statements to someone they let down. Neff and Beretvas (2012) found that women are more concerned with and attentive to the suffering of others when compared to men. Perhaps, this other-focused concern makes women more aware that self-compassionate statements could be seen as insensitive following an interpersonal transgression. Overall, women were less likely than men to endorse saying self-compassionate and self-critical statements suggesting that they were less likely to focus on the self when working to repair their relationships.

Contrary to predictions, relationship closeness did not impact participants' likelihood of endorsing self-compassionate and self-critical statements. While people tend to be more authentic with close others, we did not find support for this hypothesis in our data. Selfcompassionate participants endorsed self-compassionate responses over self-critical responses regardless of whether the transgressor was an acquaintance, close friend, or romantic partner. We also anticipated that relationship closeness might affect preference for self-compassionate versus self-critical responses from others. We found partial support for this hypothesis suggesting that people were more likely to forgive transgressors with self-critical presentations over self-compassionate presentations for close friends and acquaintances but not for romantic partners. As suggested before, the motivation to repair romantic relationships may be stronger than the motivation to repair other relationships; therefore, forgiveness is not as dependent on one's response to transgressions.

Given research showing people offer more support and forgiveness for apologies that are accompanied by self-degradation, we anticipated that participants would prefer and be more likely to forgive people who made self-critical statements as opposed to selfcompassionate statements (Powers \& Zuroff, 1988). Although this hypothesis was supported for our participants low in self-compassion, the participants high in selfcompassion preferred self-compassionate statements to self-critical statements and were equally as likely to forgive people who made one type of statement as opposed to another. 
People may prefer apologies that include self-statements mirroring their own self-attitude (Fehr \& Gelfand, 2010). Based on this finding, it might be best to know how selfcompassionate someone is before apologizing for an interpersonal transgression in order to tailor one's self-statements to that person's preferences. Because self-compassion is an observable trait (Neff \& Beretvas, 2012), people should be able to perceive selfcompassion in others, particularly those who are close to them. Although participants low in self-compassion report preferring self-criticism and being more likely to forgive people who behave self-critically, this preference could be short term. While self-criticism might lead to short-term forgiveness, over time these types of statements may lead to disrespect and loss of favor in the relationship (Powers \& Zuroff, 1988). With these long-term effects in mind, presenting self-compassionately after a transgression could have positive outcomes even when interacting with self-critical others.

\section{Limitations}

Although the research here shows self-compassion predicts self-presentations following interpersonal transgressions, these self-presentations were limited to the use of selfcompassionate and self-critical statements. It is likely that self-compassion also predicts self-presentation across a variety of other characteristics such as kindness and morality. One goal of the study was to assess whether self-compassionate individuals would selfpresent as more remorseful following an interpersonal transgression. Due to the ceiling effect on our remorsefulness variable, we were unable to test this hypothesis. The coded data suggested that self-compassionate people were not more likely to apologize, but they were less likely to want someone else to apologize for a transgression. In the future, remorsefulness should be measured using more items with larger scales in order to capture its variability.

In addition, we examined self-compassionate responses within the context of imagined scenarios that may not fully capture the complexity of a dynamic interpersonal interaction. However, we expect the artificial nature of the situation would only work to mask our effects leading us to believe that these effects would be stronger in a more realistic context. Along these lines, participants were asked to predict their response to or preference for self-compassionate and self-critical responses, and these ratings may not reflect participants' real behavior. Yet, most transgression research involves the use of imagined scenarios (Schlenker \& Darby, 1981; Gonzales, Manning, \& Haugen, 1992).

Although the instructions for study 2 asked participants to write what they would want the transgressor to say, the coded responses revealed that many participants wrote in the third person. For this reason, it was difficult to disentangle when a participant wanted the transgressor to respond self-compassionately and when the participant was showing compassion to the transgressor. Research on the relationship between self-compassion and other-oriented compassion is mixed with some studies reporting a positive correlation and others reporting no relationship (Leary et al., 2007; Neff \& Pommier, 2013). More research is needed to fully understand the dynamic interplay between self- and otheroriented compassion and how these two variables might relate to self-compassionate presentations and transgressions.

Finally, the means for one's likelihood of saying self-compassionate and self-critical statements was relatively low, suggesting that these types of statements may not be a primary response for transgressors working to repair relationships. If the primary goal is relationship repair, then the transgressor may recognize that self-statements could work counter to the other-focused concern people expect in an apology. Further, the coded selfcompassionate and self-critical responses revealed a very low hit rate, suggesting that 
participants are not as likely to verbalize self-compassion and self-criticism in their initial responses. Instead, most participants focused their responses on apologies and relationship repair with the expectation that those two elements would lead to forgiveness. Schlenker and Darby (1981) found people engage more components of an apology (e.g., selfcastigation, requests for forgiveness) when they are more at fault and their transgression has serious repercussions. It may be that the present scenario was not serious enough to elicit spontaneous self-compassionate and self-critical responses from the participants. People may only engage self-compassion and self-criticism once they see their initial attempt to elicit forgiveness has failed. Future studies should investigate these selfpresentations within a laboratory context to see the extent to which people verbalize selfcompassionate and self-critical statements.

\section{Future Directions and Conclusions}

These studies are the first to examine the self-presentational tendencies of selfcompassionate people as well as the extent to which these self-presentations are effective in earning forgiveness. Given the limited research on self-compassion and interpersonal well-being, researchers should strive to dissect how self-compassion functions in the context of dynamic social relationships. In particular, understanding how self-compassion facilitates or hinders belonging within a given situation will provide information about the adaptive nature of self-compassion and the extent to which others affect it.

This research focuses on the context of interpersonal transgressions; however, people may present a self-compassionate image under a variety of situations involving social duress. For example, people who are excluded or ignored may choose to self-present as self-compassionate in order to communicate self-acceptance and resilience. Selfcompassionate presentations may also be pertinent in situations where compassion is withheld from others or under conditions of external evaluation such as a job interview. Further, it is important to understand whether a desire for authenticity or a social incentive leads to self-compassionate presentations. In order to accurately assess the benefits and costs of being self-compassionate, we need a better understanding of how people use self-compassionate presentations and the motivations underling those presentations.

Importantly, the effects found in these studies are only generalizable to an American population. The extent to which people voice self-compassionate and self-critical statements will be dependent on the social norms of the culture and the likelihood of the statements leading to forgiveness (Neff, Pisitsungkagarn, \& Hsieh, 2008). For instance, in a culture where self-compassion is encouraged and valued, these self-presentations may be more frequent and esteemed, whereas in a culture that values a self-critical mindset, selfcompassionate statements would be counter-normative and potentially harmful to one's relationships. Because the present research found that trait self-compassion predicted preference for self-compassionate and self-critical responses, we would expect selfcompassionate responses to be preferred in a culture where self-compassion is valued and self-critical responses to be preferred where self-criticism is valued.

Investigating self-compassion within a social context is essential to understanding how self-compassion develops, when it will be reinforced, and how it affects acceptance and belonging. These studies are an initial attempt to determine whether self-compassion predicts self-compassionate presentations and how those presentations are received by others. Overall, self-compassionate people present themselves self-compassionately when they let someone down, and these presentations are received favorably when the audience member is also self-compassionate. 


\section{References}

Adams, C. E., \& Leary, M. R. (2007). Promoting self-compassionate attitudes toward eating among restrictive and guilty eaters. Journal of Social and Clinical Psychology, 26, 1120-1144. doi:10. 1521/jscp.2007.26.10.1120

Aiken, L. S., \& West, S. G. (1991). Multiple regression: Testing and interpreting interactions. Newbury Park: Sage.

Allen, A. B., Goldwasser, E. R., \& Leary, M. R. (2012). Self-compassion and well-being among older adults. Self and Identity, 11, 428-453. doi:10.1080/15298868.2011.595082

Allen, A. B., \& Leary, M. R. (2010). Self-compassion, stress, and coping. Social and Personality Psychology Compass, 4, 107-118. doi:10.1111/j.1751-9004.2009.00246.x

Allen, A. B., \& Leary, M. R. (2014). Self-compassionate responses to aging. The Gerontologist, 54, 190-200. doi:10.1093/geront/gns204

Baker, L. R., \& McNulty, J. K. (2011). Self-compassion and relationship maintenance: The moderating roles of conscientiousness and gender. Journal of Personality and Social Psychology, 100, 853-873. doi:10.1037/a0021884

Baumeister, R. F., \& Leary, M. R. (1995). The need to belong: Desire for interpersonal attachments as a fundamental human motivation. Psychological Bulletin, 117, 497-529. doi:10.1037/00332909.117.3.497

Bottom, W. P., Gibson, K., Daniels, S. E., \& Murnighan, J. (2002). When talk is not cheap: Substantive penance and expressions of intent in rebuilding cooperation. Organization Science, 13, 497-513. doi:10.1287/orsc.13.5.497.7816

Breines, J. G., \& Chen, S. (2012). Self-compassion increases self-improvement motivation. Personality and Social Psychology Bulletin, 38, 1133-1143. doi:10.1177/0146167212445599

Crocker, J., \& Canevello, A. (2008). Creating and undermining social support in communal relationships: The role of compassionate and self-image goals. Journal of Personality and Social Psychology, 95, 555-575. doi:10.1037/0022-3514.95.3.555

Darby, B. W., \& Schlenker, B. R. (1982). Children's reactions to apologies. Journal of Personality and Social Psychology, 43, 742-753. doi:10.1037/0022-3514.43.4.742

Fehr, R., \& Gelfand, M. J. (2010). When apologies work: How matching apology components to victims' self-construals facilitates forgiveness. Organizational Behavior and Human Decision Processes, 113, 37-50. doi:10.1016/j.obhdp.2010.04.002

Goffman, E. (1971). Relations in public. New York, NY: Harper Colophon Books.

Gonzales, M. H., Manning, D. J., \& Haugen, J. A. (1992). Explaining our sins: Factors influencing offender accounts and anticipated victim responses. Journal of Personality and Social Psychology, 62, 958-971. doi:10.1037/0022-3514.62.6.958

Jones, E. E., \& Pittman, T. S. (1982). Toward a general theory of strategic self-presentation. In J. Suls (Ed.), Psychological perspectives of the self (pp. 231-262). Hillsdale, NJ: Erlbaum.

Kearns, J. N., \& Fincham, F. D. (2005). Victim and perpetrator accounts of interpersonal transgressions: Self-serving or relationship-serving biases. Personality and Social Psychology Bulletin, 31, 321-333. doi:10.1177/0146167204271594

Kelly, A. C., Zuroff, D. C., Foa, C. L., \& Gilbert, P. (2010). Who benefits from training in selfcompassionate self-regulation? A study of smoking reduction. Journal of Social and Clinical Psychology, 29, 727-755. doi:10.1521/jscp.2010.29.7.727

Leary, M. R., \& Allen, A. (2011a). Belonging motivation: Establishing, maintaining, and repairing relational value. In D. Dunning (Ed.), Social motivation (pp. 37-55). New York, NY: Psychology Press.

Leary, M. R., \& Allen, A. (2011b). Personality and persona: Personality processes in selfpresentation. Journal of Personality, 79, 889-916.

Leary, M. R., Nezlek, J. B., Downs, D. L., Radford-Davenport, J., Martin, J., \& McMullen, A. (1994). Self-presentation in everyday interactions: Effects of target familiarity and gender composition. Journal of Personality and Social Psychology, 67, 664-673. doi:10.1037/00223514.67.4.664 
Leary, M. R., Tate, E. B., Adams, C. E., Allen, A., \& Hancock, J. (2007). Self-compassion and reactions to unpleasant self-relevant events: The implications of treating oneself kindly. Journal of Personality and Social Psychology, 92, 887-904. doi:10.1037/0022-3514.92.5.887

McCullough, M. E., Rachal, K. C., Sandage, S. J., Worthington, E. L. Jr, Brown, S. W., \& Hight, T. L. (1998). Interpersonal forgiving in close relationships: II. Theoretical elaboration and measurement. Journal of Personality and Social Psychology, 75, 1586-1603.

Neff, K. D. (2003). The development and validation of a scale to measure self-compassion. Self and Identity, 2, 223-250. doi:10.1080/15298860309027

Neff, K. D., \& Beretvas, S. (2012). The role of self-compassion in romantic relationships. Self and Identity, 12, 78-98. doi:10.1080/15298868.2011.639548

Neff, K. D., \& Germer, C. K. (2013). A pilot study and randomized controlled trial of the mindful self-compassion program. Journal of Clinical Psychology, 69, 28-44. doi:10.1002/jclp.21923

Neff, K. D., Hsieh, Y., \& Dejitterat, K. (2005). Self-compassion, achievement goals, and coping with academic failure. Self and Identity, 4, 263-287. doi:10.1080/13576500444000317

Neff, K. D., Kirkpatrick, K. L., \& Rude, S. S. (2007). Self-compassion and adaptive psychological functioning. Journal of Research in Personality, 41, 139-154. doi:10.1016/j.jrp.2006.03.004

Neff, K. D., Pisitsungkagarn, K., \& Hseih, Y. (2008). Self-compassion and self-construal in the United States, Thailand, and Taiwan. Journal of Cross-Cultural Psychology, 39, 267-285. doi:10.1177/0022022108314544

Neff, K. D., \& Pommier, E. (2013). The relationship between self-compassion and other-focused concern among college undergraduates, community adults, and practicing meditators. Self and Identity, 12, 160-176. doi:10.1080/15298868.2011.639548

Neff, K. D., Rude, S. S., \& Kirkpatrick, K. L. (2007). An examination of self-compassion in relation to positive psychological functioning and personality traits. Journal of Research in Personality, 41, 908-916. doi:10.1016/j.jrp.2006.08.002

Neff, K. D., \& Vonk, R. (2009). Self-compassion versus global self-esteem: Two different ways of relating to oneself. Journal of Personality, 77, 23-50. doi:10.1111/j.1467-6494.2008.00537.x

Powers, T. A., \& Zuroff, D. C. (1988). Interpersonal consequences of overt self-criticism: A comparison with neutral and self-enhancing presentations of self. Journal of Personality and Social Psychology, 54, 1054-1062. doi:10.1037/0022-3514.54.6.1054

Schlenker, B. R. (1980). Impression management: The self-concept, social identity, and interpersonal relations. Monterey: Brooks/Cole.

Schlenker, B. R., \& Darby, B. W. (1981). The use of apologies in social predicaments. Journal of Social Psychology Quarterly, 44, 271-278.

Yarnell, L. M., \& Neff, K. D. (2012). Self-compassion, interpersonal conflict resolutions, and wellbeing. Self and Identity, 12, 146-159. doi:10.1080/15298868.2011.649545 